The Journal of Laryngology \& Otology

http://journals.cambridge.org/JLO

Additional services for The Journal of Laryngology \& Otology:

Email alerts: $\underline{\text { Click here }}$

Subscriptions: $\underline{\text { Click here }}$

Commercial reprints: $\underline{\text { Click here }}$

Terms of use : $\underline{\text { Click here }}$

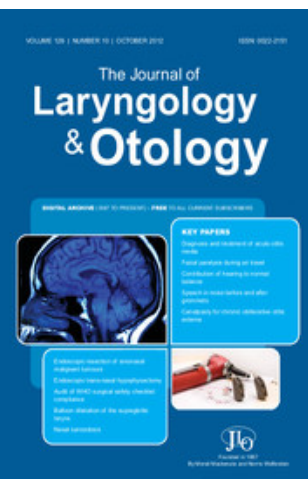

\title{
Acute bilateral vestibulo-cochlear dysfunction following occipital fracture
}

M. R. Feneley and P. Murthy

The Journal of Laryngology \& Otology / Volume 108 / Issue 01 / January 1994, pp 54 - 56

DOI: 10.1017/S0022215100125836, Published online: 29 June 2007

Link to this article: http://journals.cambridge.org/abstract S0022215100125836

How to cite this article:

M. R. Feneley and P. Murthy (1994). Acute bilateral vestibulo-cochlear dysfunction following occipital fracture. The Journal of Laryngology \& Otology, 108, pp 54-56 doi:10.1017/S0022215100125836

Request Permissions : $\underline{\text { Click here }}$ 


\title{
Acute bilateral vestibulo-cochlear dysfunction following occipital fracture
}

\author{
M. R. Feneley, M.A., F.R.C.S., P. Murthy, F.R.C.S. (Ipswich)
}

\begin{abstract}
The case of a 57-year-old man who presented with acute bilateral deafness and vestibular dysfunction following occipital bone fracture is described. Plain radiographs and a CT scan of the head demonstrated a single fracture of the occipital bone. Complete loss of cochlear and vestibular function bilaterally was demonstrated and followed by partial recovery of auditory function over the following months. Review of the literature has not revealed a previously reported case.
\end{abstract}

Key words: Deafness; Head injury; Occipital bone

\section{Case report}

A 57-year-old man was brought to hospital having sustained an occipital injury after falling against stone steps at work. He was found semiconscious some time after the accident, and had vomited on several occasions. His previous health had been excellent; he did not take any medications and never drank alcohol to excess. On arrival at hospital six hours following the accident, he was fully conscious and alert. He was nevertheless relatively uncommunicative and his speech was whispered. He indicated through writing that the accident had rendered him totally deaf.

Clinical examination demonstrated a subcutaneous occipital haematoma and complete bilateral sensorineural deafness. This was associated with truncal ataxia. Aided to an upright posture, even when seated, he would instantly fall to one or other side. An otoneurological examination revealed normal external auditory meati and tympanic membranes with no evidence of a haemotympanum, normal bilateral facial nerve function, no nystagmus and no clinical signs of temporal bone injury. Significantly, he had complete loss of VIIIth nerve function bilaterally and signs of cerebellar dysfunction.

Skull radiographs demonstrated a linear fracture of the occipital bone extending inferiorly from the sagittal suture towards the skull base. This was confirmed by a CT scan which showed no evidence of intracranial haematoma or other cerebral abnormality and the petrous temporal bones appeared intact with normal aeration of the middle ear cavities. A pure tone audiogram performed three days following the injury showed no response whatsoever in either ear. Bithermal air caloric tests at $20^{\circ}$ and $49^{\circ} \mathrm{C}$ elicited no response from either vestibular system indicating a bilateral canal paresis. Brain stem-evoked response audiometry did not derive any clear responses from either ear at maximum stimulation. Results of acoustic impedance measurements were within normal limits.

Over the following days, his speech remained whispered. Although able to sit, he remained unsteady on his feet with support. Three weeks following the injury, the first sign of return of auditory function was apparent, the hearing in the right ear returning to $60 \mathrm{~dB}$ at $250 \mathrm{~Hz}$, although the curve tailed off sharply and was unrecordable at frequencies greater than $1 \mathrm{kHz}$ (Figure 1).
Over the next six months, there was partial recovery of vesibular and cochlear function in both ears (Figure 2). Caloric testing six months following the injury indicated bilateral labyrinthine hypofunction with minimal responses from both vestibules. With partial recovery of hearing particularly in the right ear, he has derived good benefit from a hearing aid and is also slightly less dizzy.

\section{Discussion}

Hearing loss is well described when associated with temporal bone fractures (Liu-Shindo and Hawkins, 1989; McGuirt and Stool, 1992; Williams et al., 1992). This is mainly unilateral and frequently associated with signs of vestibular and facial nerve dysfunction. The mechanisms of sensorineural deafness following this type of injury are generally well recognized resulting from either a concussional injury to the vestibulo-cochlear system inflicting maximum damage on the basal turn of the cochlear and occasional acute haemorrhage therein, axonal injury to the fibres of the VIIIth nerve in the fracture line causing laceration and haemorrhage into its substance (Ludman, 1988), or disruption of the membranous labyrinth with fibrosis, scarring and labyrinthitis ossificans (Schuknecht, 1969). The sensorineural deafness is almost always permanent although there may be partial recovery with time.

Our case report describes a patient who had sustained trauma to the back of the head centred on the external occipital protuberance. He had no clinical or radiological signs of temporal bone fracture; this was confirmed by high resolution computerized tomography which is the most sensitive method for the imaging and clarification of temporal bone fractures (Nurre et al., 1988; Fritz et al., 1989; Ghorayeb and Rafie, 1989). He sustained bilateral sensorineural hearing loss associated with signs of cerebellar and vestibular dysfunction. His vestibular symptoms gradually improved in due course. This is a well recognized feature in most cases as the vestibular system is not as vulnerable as the auditory system although the mechanism of injury is not as clear (Wennmo and Svensson, 1989). His hearing levels did improve with the passage of time but he was still left with a severe bilateral sensorineural deafness, though fortunately he was able to benefit from a hearing aid. This emphasizes the importance of routine post-traumatic audiograms to monitor 

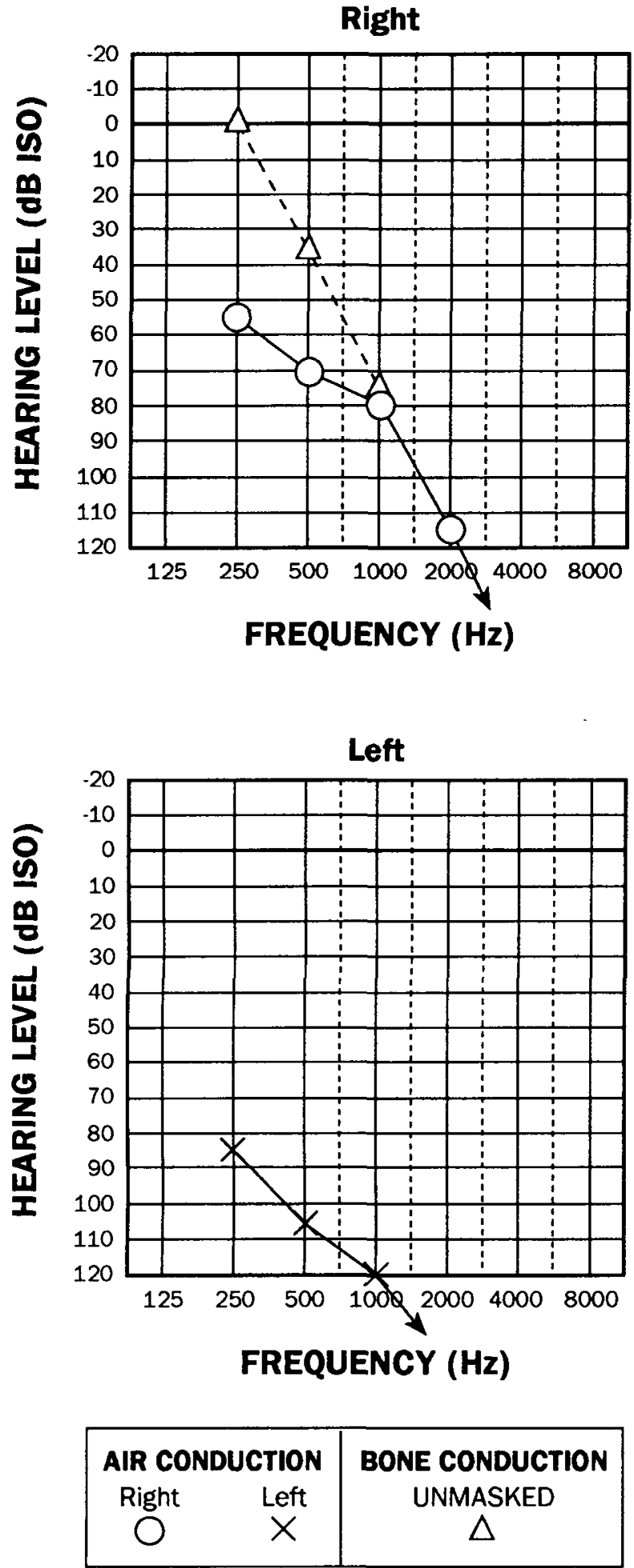

FIG. 1

Bilateral audiograms three weeks after injury.

change in hearing levels especially with variable hearing in the two ears (Scholer et al., 1990).

The mechanism of the injury to the vestibulo-cochlear system in this case is quite bizarre. The most likely explanation is a combination of central and peripheral damage to the labyrinth, resulting in both concussional and permanent axonal damage to the cerebellum, VIIIth nerve, cochlea and vestibule. We postulate that one of the effects of the blow on the back of the head was neuropraxic damage to the cerebellum and its connections with the vestibular nuclei. This may well account for the initial pres- entation of ataxia, pendular reflexes and unsteadiness which subsequently recovered on resolution of the concussional effects of the injury. The bilateral sensorineural hearing loss is more difficult to explain. This may be accounted for by the effects of inertial movements of the brain triggered by the external blow on the skull causing twisting of the brain stem and stretching and tearing of the VIIIth nerve fibres on both sides. Slow healing of the fibres affected by axonotmesis may account for the eventual partial recovery of function.

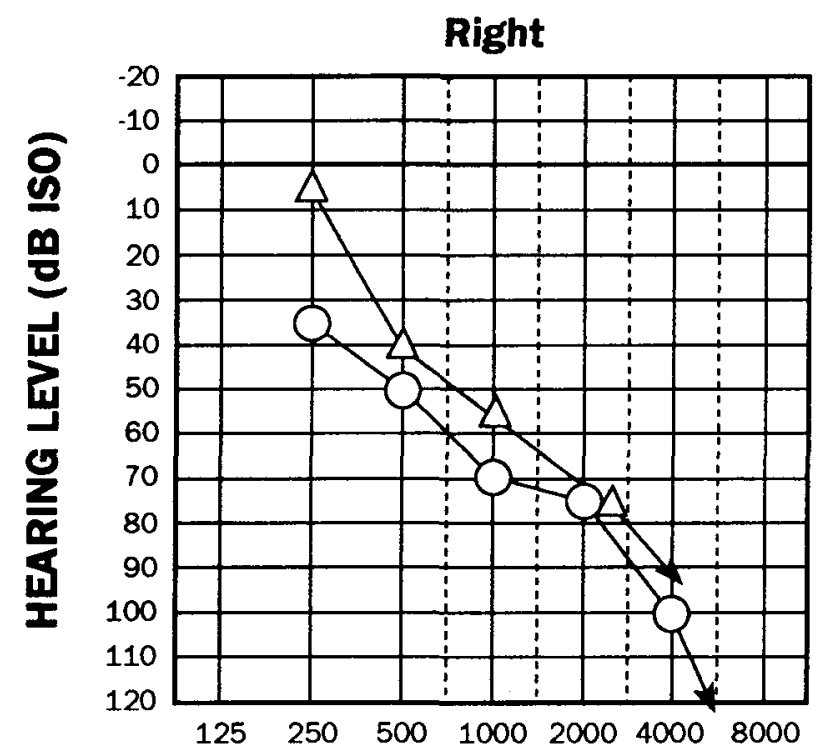

FREQUENCY $(\mathrm{Hz})$
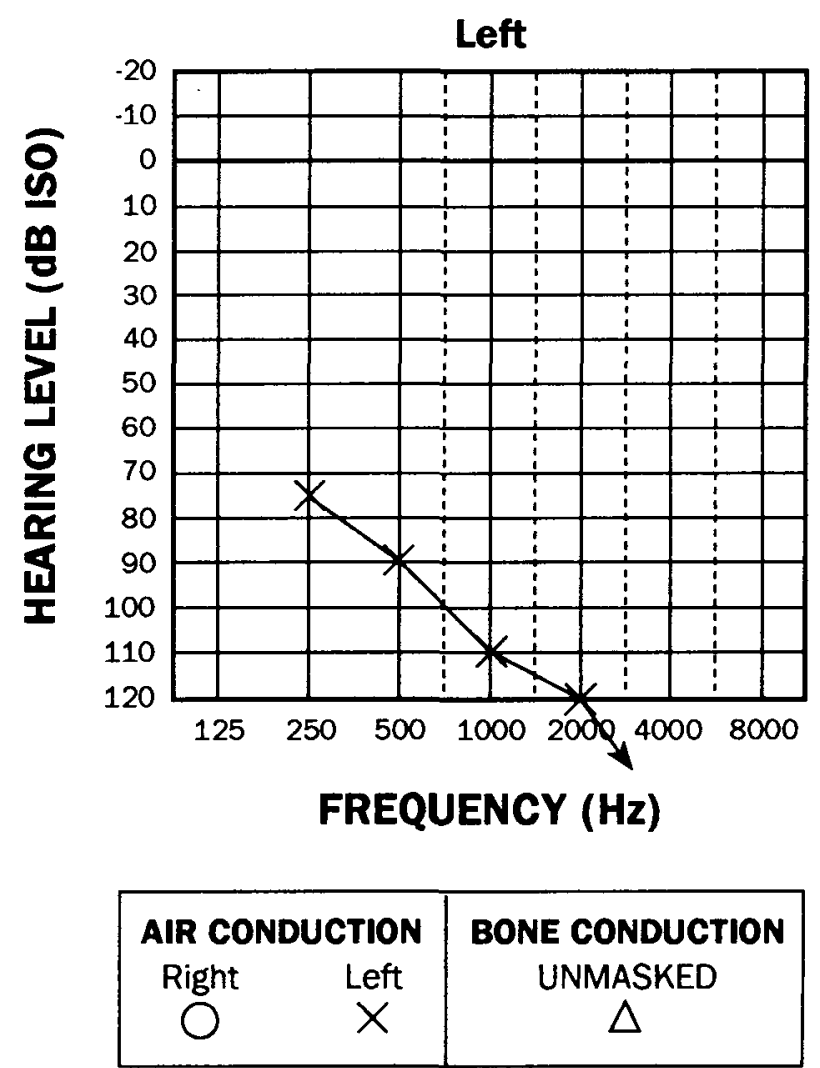

FIG. 2

Bilateral audiograms six months after injury. 


\section{Acknowledgements}

The authors would like to thank Mr I. H. K. Scott, F.R.C.S., and Mr I. J. Lord, F.R.C.S., of the Ipswich Hospital for their help and advice.

\section{References}

Fritz, P., Reiden, K., Lenarz, T., Haels, J., Zum Winkel, K. (1989) Radiological evaluation of temporal bone disease: high resolution computed tomography versus conventional X-ray diagnosis. British Journal of Radiology 62: 107-113.

Ghorayeb, B. Y., Rafie J. J. (1989) Fracture of the temporal bone. Evaluation of 123 cases. Journal de Radiologie 70: 703-710.

Liu-Shindo, M., Hawkins, D. B. (1989) Basilar skull fractures in children. International Journal of Paediatric Otorhinolaryngology 17: 109-117.

Ludman, H. (1988) Mawson's Diseases of the Ear. 5th Edition. Edward Arnold, London, p 600

McGuirt, W. F., Stool, S. E. (1992) Temporal bone fractures in children: a review with emphasis on long term sequelae. Clinical Paediatrics 31: 12-18.
Nurre, J. W., Miller, G. W., Ball, J. B. Jr. (1988) Pneumolabyrinth as a late sequela of temporal bone fracture. American Journal of Otology 9: 489-493.

Scholer, W., Moser, K. L., Poigenfurst, J. (1990) Hearing disorders after cranial trauma. Zeitschrift für Unfallchirurgie und Versicherungsmedizin 83: 237-243.

Schuknecht, H. F. (1969) Mechanisms of inner ear injury from blows to the head. Annals of Otology 78: 253-262.

Wennmo, C., Svensson, C. (1989) Temporal bone fractures. Vestibular and other related ear sequelae. Acta Oto-Laryngologica 468 (suppl.): 379-383.

Williams, W. T., Ghorayeb, B. Y., Yeakley, J. W. (1992) Paediatric temporal bone fractures. Laryngoscope 102: 600-603.

Address for correspondence:

M. R. Feneley, M.A., F.R.C.S.,

Department of Urology,

St Bartholomew's Hospital,

West Smithfield

London EC1A 7BE. 